\section{Relationships between Jasmonates and Chilling Injury in Mangosteens Are Affected by Spermine}

\author{
Satoru Kondo ${ }^{1}$ and Anan Jitratham \\ Graduate School of Applied Biosciences, Hiroshima Prefectural University, \\ Shobara, Hiroshima 727-0023, Japan
}

\section{Monrudee Kittikorn and Sirichai Kanlayanarat \\ Division of Postharvest Technology, King Mongkut's University of Technology Thonburi, Bangkok 10150, Thailand \\ Additional index words. chilling injury, Garcinia mangostana, jasmonic acid, methyl jasmonate, polyamines}

\begin{abstract}
Effects of low temperature and chilling injury (CI) on jasmonic acid (JA) and methyl jasmonate (MeJA) concentrations were investigated in mangosteens (Garcinia mangostana $\mathrm{L}$.). JA concentrations in the skin of fruit stored at $7^{\circ} \mathrm{C}$ increased significantly compared with that of those stored at $13{ }^{\circ} \mathrm{C}$, but JA decreased with the occurrence of visible symptoms of CI. Neither an increase in JA nor CI was detected in pulp of fruit stored at $7{ }^{\circ} \mathrm{C}$. JA concentrations in the skin of fruit treated with spermine (Spm) and stored at $7{ }^{\circ} \mathrm{C}$ also increased, but at a lesser extent than in untreated fruit. Thus, the response of JA to low temperatures appears to be limited to chill-susceptible parts of the fruit. The decrease of JA and the onset of CI was delayed in fruit treated with Spm kept at $7{ }^{\circ} \mathrm{C}$ compared with untreated control fruit. Exogenous application of $\boldsymbol{n}$-propyl dihydrojasmonate, which is a jasmonic acid derivative, effectively decreased CI. These results suggest that low temperature-induced JA accumulation may play a protective role against $\mathrm{CI}$. The application of jasmonates may increase chill-resistance in fruit.
\end{abstract}

Jasmonates-jasmonic acid (JA) and methyl jasmonate (MeJA) - have a role in the inhibition of growth (Tsai et al., 1997), leaf yellowing (Tsai et al., 1996), and stomatal closure (Riov et al., 1990) of plants. The effects of jasmonates in fruit have also been examined. For instance, jasmonates influenced ethylene production either positively or negatively, depending on the fruit developmental stage in apples [Malus sylvestris (L.) Mill. var. domestica (Borkh.) Mansf.] (Saniewski et al., 1986). The role of jasmonates may vary among fruit because changes in jasmonates differ between climacteric and nonclimacteric fruit types (Kondo et al., 2000). Jasmonates may also have a role as protective substances against stress. MeJA application reduced chilling injury (CI) in tomatoes (Lycopersicon esculentum L.) and papayas (Carica papaya L.) (Ding et al., 2001; Gonzalez-Aguilar et al., 2003). However, the effect of chilling temperature on endogenous jasmonates in fruit is not clear.

Marketability of mangosteens decreases when fruit are stored below $8{ }^{\circ} \mathrm{C}$ because of CI development in the skin (Augustin and Azudin, 1986). Production of stress ethylene, which caused stresses, differs according to the particular stress (Saltveit, 1992). Although jasmonates may be involved in stress resulting from both low temperatures and CI, the degree of response may differ. Polyamines are generally abundant in immature tissues

Received for publication 1 Sept. 2003. Accepted for publication 4 Dec. 2003

${ }^{1}$ To whom reprint requests should be addressed; e-mail s-kondo@bio.hiroshima-pu.ac.jp. and exogenous application of polyamines has an antisenescence effect (Kaur-Sawhney and Galston, 1991). Furthermore, polyamines have the effect of protecting membrane lipids from peroxidation (Kramer and Wang, 1989). Spermine $(\mathrm{Spm})$ applications after harvest inhibited CI in squashes (Cucurbita pepo L.) (Kramer and Wang, 1989) and decreased CI in mangosteens (Kondo et al., 2003). If the reaction of JA depends not on the low temperature treatment but on the potential for CI, polyamine application that decreases $\mathrm{CI}$ at low temperatures may influence the response of endogenous jasmonates. In this study, the effects of low temperature and $\mathrm{CI}$ on endogenous jasmonates were investigated in the skin and pulp of mangosteens. Furthermore, the influence of Spm on CI and on chilling-induced changes in JA were examined.

Fig. 1. Degree of chilling injury: (A) in skin of untreated mangosteens stored at 7 and $13{ }^{\circ} \mathrm{C}$, or after fruit were dipped in $10 \mathrm{mM}$ spermine (Spm) and stored at $7{ }^{\circ} \mathrm{C}$ (2001); (B) in skin of mangosteens dipped in $0.39 \mathrm{~mm} n$-propyl dihydrojasmonate (PDJ) and stored at $7{ }^{\circ} \mathrm{C}$ (2003). Data are the means of 12 fruit. Index of $\mathrm{CI}$ is as follows: $0=$ no chilling injury; $1=$ less than $25 \%$ skin area; $2=25 \%$ to $50 \%$ skin area; $3=$ more than $50 \%$ skin area. The photograph on the right shows chill-injured fruit with a CI index of 3 , after $24 \mathrm{~d}$ at $7^{\circ} \mathrm{C}$. The photograph on the left is of normal fruit with a CI index of 0 , after $24 \mathrm{~d}$ at $13{ }^{\circ} \mathrm{C}$.

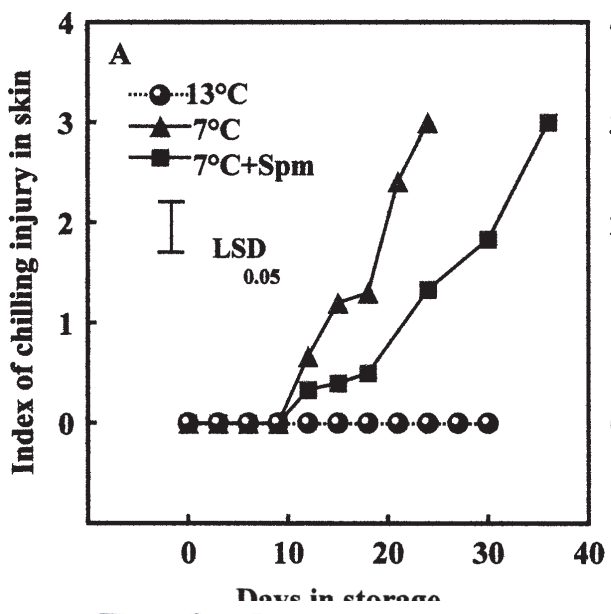

Days in storage
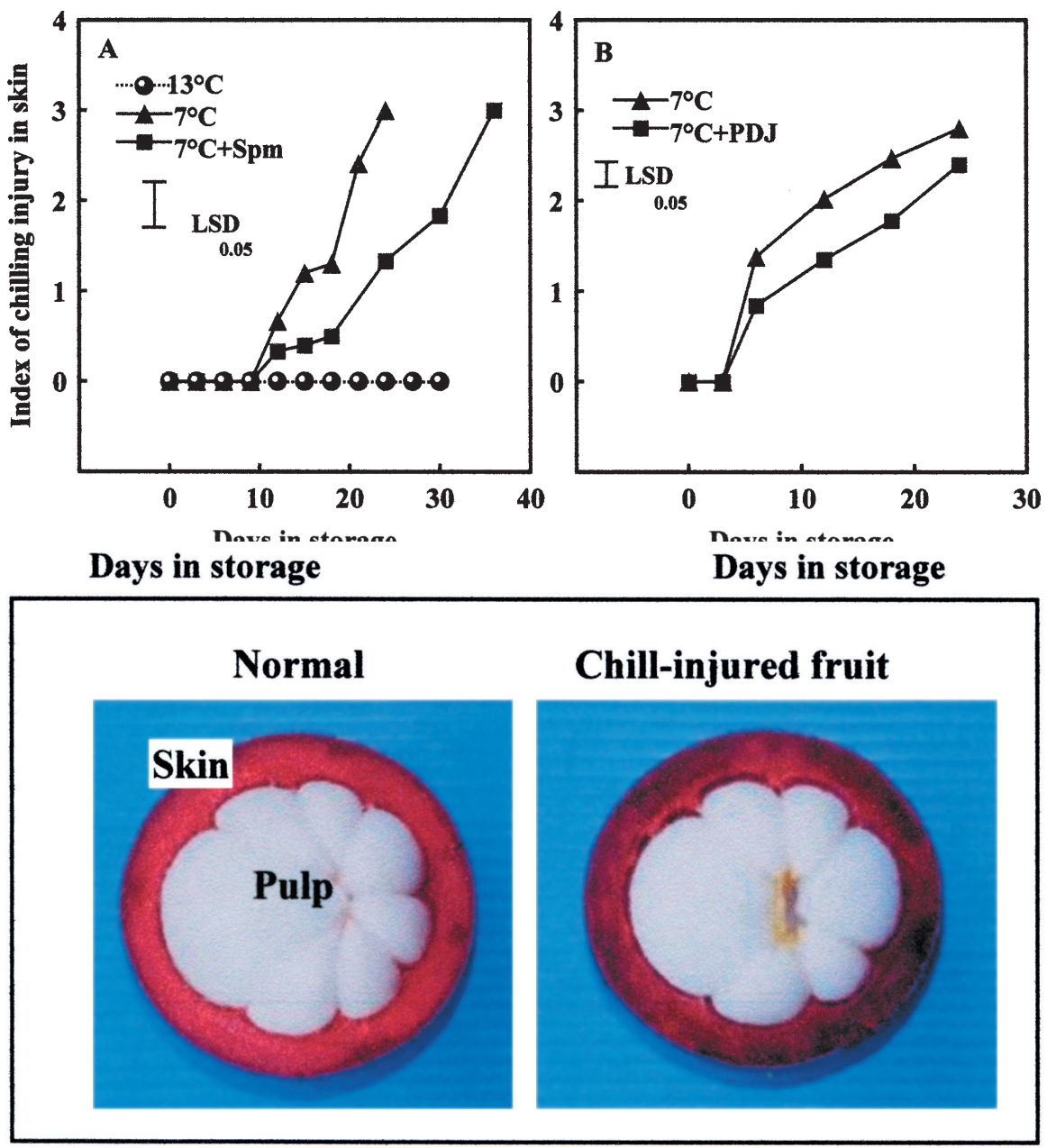


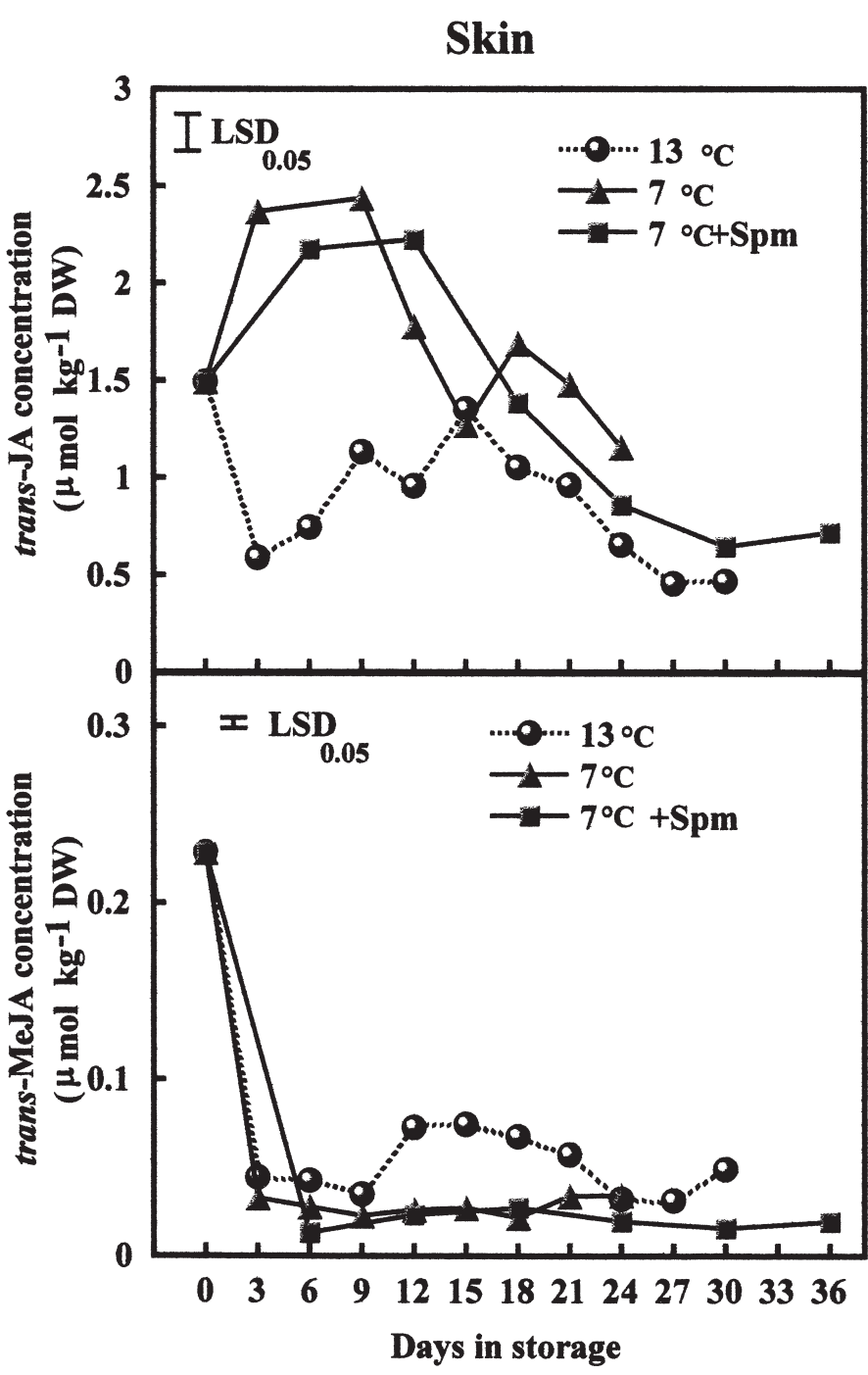

Fig. 2. Endogenous jasmonate concentrations in the skin of mangosteens stored at 7 and $13{ }^{\circ} \mathrm{C}$ and in mangosteens treated with $\mathrm{Spm}$ before being stored at $7{ }^{\circ} \mathrm{C}$. Data are the means of three replications.

\section{Materials and Methods}

Chemicals. Spm was purchased from Sigma-Aldrich Co. (St. Louis). $n$-Propyl dihydrojasmonate (PDJ), which is a JA derivative, was provided by Nippon Zeon Co. (Tokyo).

Plant material and evaluation of chilling injury. Three randomly selected 6- or 8-year-old mangosteen trees of a local cultivar (described cultivars are not reported) in an orchard in Rayong province, Thailand, were used in this experiment in 2001 and 2003. At $84 \mathrm{~d}$ after full bloom (DAFB) in 2001, 360 fruit (120 fruit per tree) were harvested and randomly divided into three groups, then stored as follows: 1) $85 \%$ to $90 \%$ relative humidity $(\mathrm{RH})$ at $13{ }^{\circ} \mathrm{C}$; 2) $85 \%$ to $90 \% \mathrm{RH}$ at $7{ }^{\circ} \mathrm{C}$; and 3 ) $85 \%$ to $90 \% \mathrm{RH}$ at $7{ }^{\circ} \mathrm{C}$ after an application of $10 \mathrm{~mm}$ Spm. The latter fruit were dipped into Spm solution for $15 \mathrm{~min}$ at $25^{\circ} \mathrm{C}$ immediately after harvest and then transferred to $7^{\circ} \mathrm{C}$. The untreated control fruit were dipped into distilled water in the same manner. CI in mangosteens is expressed as browning of the skin and high fruit firmness (Augustin and Azudin, 1986).

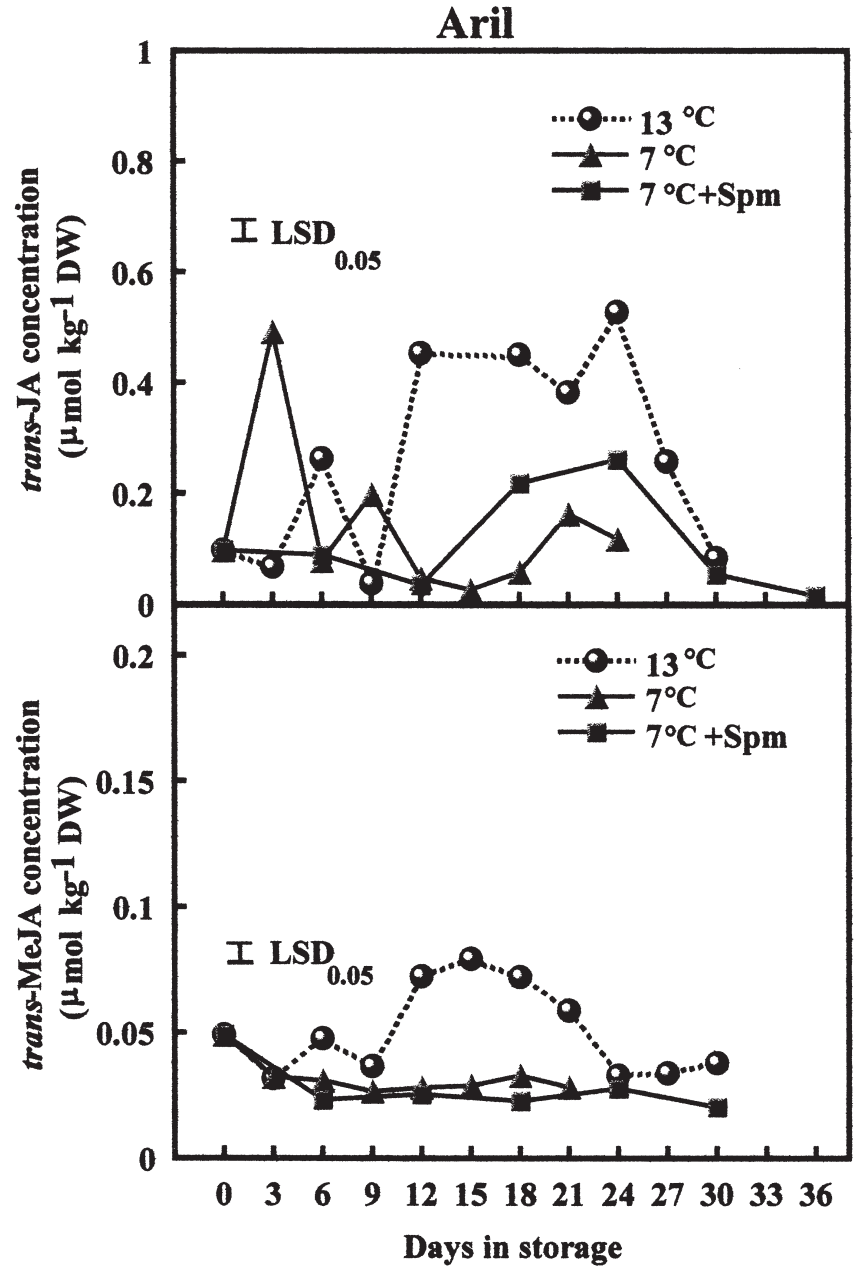

CI was evaluated at 3- to 6-d intervals during storage by the degree of skin browning where 0 indicated no CI; $1=$ less than $25 \%$ of skin area; $2=25 \%$ to $50 \%$ of skin area; and $3=$ more than $50 \%$ skin area. The fruit in which the aril was offflavor became inedible. After fruit from each group was evaluated for CI, the skin without the outermost woody tissue and aril samples were separated and immediately frozen in liquid $\mathrm{N}_{2}$ and lyophilized. The samples were stored at $-30{ }^{\circ} \mathrm{C}$, then flown to Hiroshima on dry ice for analysis at Hiroshima Prefectural University. The effect of exogenous application of jasmonates on CI was examined (2003) using PDJ, which has a stable effect on fruit setting, fruit growth, and ripening compared with the MeJA of the natural type (Fujisawa et al., 1997). In total, 240 fruit (80 fruit per tree) were harvested at 84 DAFB, as in the 2001 study, then randomly divided into two groups of 120 fruit, one treated with PDJ and the other an untreated control group. The first group was dipped into $0.39 \mathrm{~mm}$ PDJ solution for $15 \mathrm{~min}$ at $25{ }^{\circ} \mathrm{C}$ immediately after harvest and then stored at $7{ }^{\circ} \mathrm{C}$. The second group was dipped into distilled water and then stored at $7{ }^{\circ} \mathrm{C}$.

Jasmonate analysis. Deuterium labeled jasmonic acid (JA) $\left[\left({ }^{2} \mathrm{H}_{2}\right)-\mathrm{JA}:( \pm)-\left[9,10-{ }^{2} \mathrm{H}_{2}\right]\right.$ JA $]$ and its methyl ester $\left[\left({ }^{2} \mathrm{H}_{2}\right)\right.$-MeJA: methyl $( \pm)-\left[9,10-{ }^{2} \mathrm{H}_{2}\right]$ jasmonate $]$ were synthesized from adipic acid through catalytic semi-deu-
Fig. 3. Endogenous jasmonate concentrations in the aril of mangosteens stored at 7 and $13^{\circ} \mathrm{C}$ or after dipping of fruit in Spm and stored at $7^{\circ} \mathrm{C}$. Data are the means of three replications.

teriogenation of methyl ( \pm )-9, 10-dehydrojasmonate, for use of internal standards (Seto et al., 1996). Mangosteen fruit contains cis-JA, cis-MeJA, trans-JA, and trans-MeJA (Kondo et al., 2000), but trans-JA and MeJA were analyzed here because most $c i s$-isomers shift to trans-isomers during extraction (Yamane, 1995). JA and MeJA were extracted as previously described (Kondo et al., 2000), using $1 \mu \mathrm{g}\left({ }^{2} \mathrm{H}_{2}\right)$ JA and $\left({ }^{2} \mathrm{H}_{2}\right)$ MeJA as internal standards. The sample was analyzed by gas chromatography-mass spectrometry-selected ion monitoring (GC-MS-SIM) (QP 5000; Shimadzu, Kyoto, Japan) equipped with CPSil 5 CB column (Chrompack, Middelburg, Netherlands; $0.25 \mathrm{~mm}$ i.d. $\times 25 \mathrm{~m}, 0.25-\mu \mathrm{m}$ film thickness). The analysis conditions were as follows; linear He flow at $50.2 \mathrm{~cm} \cdot \mathrm{s}^{-1}$, column temperature step gradient, $60{ }^{\circ} \mathrm{C}$ for $2 \mathrm{~min}$, 60 to $270{ }^{\circ} \mathrm{C}$ at $10^{\circ} \mathrm{C} \cdot \mathrm{min}^{-1}$, and $270{ }^{\circ} \mathrm{C}$ for $35 \mathrm{~min}$; electron potential, $70 \mathrm{eV}$. Retention time for the derivative of trans-JA is 19.65 min and that of trans-MeJA is $14.25 \mathrm{~min}$. JA and $\left[{ }^{2} \mathrm{H}_{2}\right]( \pm)$-JA were analyzed by ions of $\mathrm{m} / \mathrm{z}, 390,392,209$, and 211. JA concentrations were calculated from the ratio of peak areas for $m / z, 390\left({ }^{2} \mathrm{H}_{0}\right) / 392\left({ }^{2} \mathrm{H}_{2}\right)$. MeJA and [2H2] ( \pm )-MeJA were analyzed by ions of $\mathrm{m} / \mathrm{z}$. 
224, 226, 151, and 153. MeJA concentrations were calculated from the ratio of peak areas for $m / z, 224\left({ }^{2} \mathrm{H}_{0}\right) / 226\left({ }^{2} \mathrm{H}_{2}\right)$. Mean values in Figs. 1, 2, and 3 were subjected to analysis of variance (ANOVA) and separated by LSD, $P$ $\leq 0.05$ (SAS, Cary, N.C.).

\section{Results and Discussion}

CI was not observed at $13{ }^{\circ} \mathrm{C}$, while it increased rapidly after $9 \mathrm{~d}$ at $7^{\circ} \mathrm{C}$ (Fig. 1). By contrast, the pulp did not show chilling damage during fruit storage at $7{ }^{\circ} \mathrm{C}$. Spm application at $7{ }^{\circ} \mathrm{C}$ reduced CI compared with the untreated control. Fruit became inedible after $30 \mathrm{~d}$ storage at $13{ }^{\circ} \mathrm{C}$ and after $24 \mathrm{~d}$ at $7{ }^{\circ} \mathrm{C}$. However, no inedible fruit were detected till $36 \mathrm{~d}$ storage at $7{ }^{\circ} \mathrm{C}$ in Spm-treated mangosteens. In both the skin and aril, JA concentrations were higher than those of MeJA (Figs. 2 and 3). This result is consistent with apples, sweet cherries (Prunus avium L.), and grape berries (Vitis spp.) (Kondo and Fukuda, 2001; Kondo et al., 2000).

JA concentrations in the skin of fruit stored at $7^{\circ} \mathrm{C}$ were consistently higher than those stored at $13^{\circ} \mathrm{C}$. JA sharply increased for up to 3 d storage at $7^{\circ} \mathrm{C}$ and the concentration remained especially high until $9 \mathrm{~d}$ at this temperature. The chilling-induced increase in JA was lower in Spm-treated fruit, but JA levels remained high until $12 \mathrm{~d}$ at $7{ }^{\circ} \mathrm{C}$. It has been shown that wounding stress increased jasmonate levels in detached petunia corollas (Petunia hybrida L.) (Tamari et al., 1995). Increased JA in low temperature-stored mangosteens suggests that $\mathrm{JA}$ is involved in low temperature stress. The exogenous application of PDJ decreased CI in the skin (Fig. 1). The mechanism of JA against $\mathrm{CI}$ is unclear. It has been observed that PDJ application in the blooming period decreased spring frost injury in Japanese pears (Pyrus pyrifolia Nakai) (Sekozawa et al., 2003). It was concluded that the increase of sugar content in the PDJ-treated flower was related to the alleviation of frost injury. Although it is assumed that high sugar concentrations in cell sap lowered the freezing temperature, this mechanism may not apply to fruit after harvest that are no longer connected to the plant's flow of nutrients. Wounding increased jasmonate levels and revealed genes of biosynthetic defensive substances (Seo et al., 1997). MeJA application to soybean (Glycine $\max$ L.) suspension cultures increased the levels of mRNA for wound-responsive genes (Creelman et al., 1992). These reports suggest the presence of genes responding to low temperatures, although this has not been explicitly reported. When both chilling-resistant and chilling-sensitive rice cultivars were chilled at $5{ }^{\circ} \mathrm{C}$, putrescine levels in chilling-resistant rice cultivars increased compared to those of chilling-sensitive rice cultivars (Lee et al., 1995). A similar result has been reported in Phaseolus sp. (Guye et al., 1986). These observations suggest that the increase of polyamines under low temperatures may be involved in resistance to CI development. Jasmonates may play a role against CI as well as polyamines (Gonzalez-Aguilar et al., 2001). The reduction of CI by PDJ application provides evidence to support a role of jasmonates on CI. Jasmonate treatment induced an increase in polyamines in tobacco leaf discs (Nicotiana tabacum L.), barley seedlings (Hordeum vulgare L.), and squash (Biondi et al., 2003; Walters et al., 2002; Wang and Buta, 1994). Therefore, jasmonate treatment may increase polyamine levels, resulting in the increase of the tolerance of fruit to chilling. Spm application reduced CI and the increase in JA at $7^{\circ} \mathrm{C}$ (Figs. 1 and 2). Spm may reduce the initial chilling-induced increase in JA by increasing the tolerance of mangosteen fruit to chilling. However, when CI occurred in the skin of fruit stored at $7{ }^{\circ} \mathrm{C}$, JA levels fell rapidly. At $7^{\circ} \mathrm{C}$, the reduction of JA and the onset of CI was delayed in the skin of fruit treated with Spm compared with that of the skin from the untreated control. These facts suggest that jasmonate levels increase to protect fruit against chilling, but that its role diminishes after CI has occurred.

JA concentrations in the aril were lower than those in the skin. JA concentrations did not differ according to temperature until day 9, but after this time JA levels were the highest at $13{ }^{\circ} \mathrm{C}$. The second highest was at $7^{\circ} \mathrm{C}$ with Spm treatment, and the lowest was at 7 ${ }^{\circ} \mathrm{C}$. Therefore, jasmonates did not respond to low temperatures in the pulp, which did not show CI, and may be strictly associated with the chill-sensitive part of the fruit. JA accumulations in the pulp at $13{ }^{\circ} \mathrm{C}$ were not studied. However, our previous report (Kondo et al., 2000) concluded that although jasmonates were associated with fruit ripening and senescence in climacteric fruit, jasmonates had no such role in nonclimacteric fruit like mangosteens. Therefore, it is assumed that high JA levels at $13^{\circ} \mathrm{C}$ after $9 \mathrm{~d}$ in storage are not related to the fruit senescence.

In summary, chilling temperature at $7{ }^{\circ} \mathrm{C}$ increased endogenous JA concentrations in the skin. The chilling-induced increase in JA was lower in Spm-treated fruit. The treatments of $0.39 \mathrm{~mm}$ PDJ and $10 \mathrm{~mm}$ Spm could be used to decrease CI development.

\section{Literature Cited}

Augustin, M.A. and M.N. Azudin. 1986. Storage of mangosteen (Garcinia mangostana L.). ASEAN Food J. 2:78-80.

Biondi, S., V. Scoccianti, S. Scaramagli, V. Ziosi, and P. Torrigiani. 2003. Auxin and cytokinin modify methyl jasmonate effects on polyamine metabolism and ethylene biosynthesis in tobacco leaf discs. Plant Sci. 165:95-101.

Creelman, R.A., M.L. Tierney, and J.E. Mullet. 1992. Jasmonic acid/methyl jasmonate accumulate in wounded soybean hypocotyls and modulate wound gene expression. Proc. Natl. Acad. Sci. USA 89:4938-4941.

Ding, C.K., C.Y. Wang, K.C. Gross, and D.L. Smith. 2001. Reduction of chilling injury and transcript accumulation of heat shock proteins in tomato fruit by methyl jasmonate and methyl salicylate. Plant Sci. 161:1153-1159.

Fujisawa, H., M. Koshiyama, H. Seto, S. Yoshida, and Y. Kamuro. 1997. Effects of jasmonic acid compound on fruit setting, fruit growth, ripening and cold-resistance. Acta Hort. 463:261-266.

Gonzalez-Aguilar, G.A., J.G. Buta, and C.Y. Wang. 2001. Methyl jasmonate reduces chilling injury symptoms and enhances colour development of 'Kent' mangoes. J. Sci. Food Agr. 81:1244-1249.
Gonzalez-Aguilar, G.A., J.G. Buta, and C.Y. Wang. 2003. Methyl jasmonate and modified atmosphere packaging (MAP) reduce decay and maintain postharvest quality of papaya 'Sunrise.' Postharvest Biol. Technol. 28:361-370.

Guye, M.G., L. Vigh, and J.M. Wilson. 1986. Polyamine titre in relation to chill-sensitivity in Phaseolus sp. J. Expt. Bot. 180:1036-1043.

Kaur-Sawhney, R. and A.W. Galston. 1991. Physiological and biochemical studies on the anti-senescence properties of polyamines in plants, p. 201-211. In: R.D. Slocum and H.E. Flores (eds.). Biochemistry and physiology of polyamines in plants. CRC Press, Boca Raton, Fla.

Kondo, S. and K. Fukuda. 2001. Changes of jasmonates in grape berries and their possible roles in fruit development. Scientia Hort. 91:275-288.

Kondo, S., A. Tomiyama, and H. Seto. 2000. Changes of endogenous jasmonic acid and methyl jasmonate in apples and sweet cherries during fruit development. J. Amer. Soc. Hort. Sci. 125:282-287.

Kondo, S., W. Ponrod, S. Kanlayanarat, and N. Hirai. 2003. Relationship between ABA and chilling injury in mangosteen fruit treated with spermine. Plant Growth Regulat. 39:119-124.

Kramer, G.F. and C.Y. Wang. 1989. Correlation of reduced chilling injury with increased spermine and spermidine levels in zucchini squash. Physiol. Plant. 76:479-484.

Lee, T.M., H.S. Lur, and C. Chu. 1995. Abscisic acid and putrescine accumulation in chilling tolerant rice cultivars. Crop Sci. 35:502-508.

Riov, J., E. Dagan, R. Goren, and S.F. Yang. 1990 Characterization of abscisic acid-induced ethylene production in citrus leaf and tomato fruit tissues. Plant Physiol. 92:48-53.

Saltveit, M.E., Jr. 1992. Regulation of ethylene production by internal, environmental and stress factors, p. 56-119. In: F.B. Abeles, P.W. Morgan, and M.E. Saltveit, Jr. (eds.). Ethylene in plant biology. Acad. Press, San Diego, Calif.

Saniewski, M., J. Nowacki, E. Lange, and J. Czapski. 1986. The effect of methyl jasmonate on ethylene and 1-aminocyclopropane-1-carboxylic acid production in preclimacteric and postclimacteric 'Jonathan' apples. Fruit Sci. Rpt. 13:193-200.

Sekozawa, Y., S. Sugaya, H. Gemma, and S. Iwahori. 2003. Cold tolerance in 'Kousui' Japanese pear and possibility for avoiding frost injury by treatment with $n$-propyl dihydrojasmonate. HortScience 38:288-292.

Seo, S., H. Sano, and Y. Ohashi. 1997. Antagonistic relationship of salicylic acid and jasmonic acid as signal molecules in resistance to pathogen attack and wounding. Chem. Regulat. Plants 32:37-48.

Seto, H., S. Fujioka, H. Fujisawa, K. Goto, H. Nojiri, H. Yamane, and S. Yoshida. 1996. Preparation of $( \pm)-2-\left(2,3-{ }^{2} \mathrm{H}_{2}\right)$ jasmonic acid and its methyl ester, methyl $( \pm)-2-\left(2,3-{ }^{2} \mathrm{H}_{2}\right)$ jasmonate. Biosci. Biotech. Biochem. 60:1709-1711.

Tamari, G., A. Borochov, R. Atzorn, and D. Weiss. 1995. Methyl jasmonate induces pigmentation and flavonoid gene expression in petunia corollas: A possible role in wound response. Physiol. Plant. 94:45-50.

Tsai, F.Y., K.T. Hung, and C.H. Kao. 1996. An increase in ethylene sensitivity is associated with jasmonate promoted senescence of detached rice leaves. J. Plant Growth Regulat. 15:197-200.

Tsai, F.Y., C.C. Lin, and C.H. Kao. 1997. A comparative study of the effects of abscisic acid and methyl jasmonate on seedling growth of rice. Plant Growth Regulat. 21:37-42.

Walters, D., T. Cowley, and A. Mitchell. 2002. Methyl jasmonate alters polyamine metabolism and induces systemic protection against powdery mildew infection in barley seedlings. J. Expt. Bot. 53:747-756.

Wang, C.Y. and J.G. Buta. 1994. Methyl jasmonate reduces chilling injury in Cucurbita pepo through its regulation of abscisic acid and polyamine levels. Environ. Expt. Bot. 34:427-432.

Yamane, H. 1995. Biosynthesis of jasmonic acid and its regulation. Chem. Regulat. Plants 30:141-143. 